\title{
Further Definition of Lipid-Lipoprotein Abnormalities in Children with Various Degrees of Chronic Renal Insufficiency
}

\author{
G. ZACChELlO, A. PAGNAN, M. P. SIDRAN, L. ZIRON, M. BRAGGION, L. PAVANELLO, AND \\ P. FACCHIN \\ Dipartimento di Pediatria, Cattedra di Clinica Medica, Università degli Studi di Padova, Padova, \\ Italy [A.P., L.Z., M.B.]
}

\begin{abstract}
We characterized the lipid-lipoprotein abnormalities encountered in a series of 45 nonnephrotic uremic children with various degrees of chronic renal insufficiency. A mild hypertriglyceridemia associated with decreased serum high-density lipoprotein cholesterol levels was confirmed. The correlation between high-density lipoprotein cholesterol and creatinine clearance showed a power behavior with a marked decrease in high-density lipoprotein cholesterol below a creatinine clearance value of $40 \mathrm{ml} / \mathrm{min} / 1.73 \mathrm{~m}^{2}$. A number of uremic children accumulate an abnormal population of very low-density lipoprotein particles in their plasma. On agarose gel electrophoresis these particles migrate as a slow moving pre- $\beta$ band and are clearly distinguished from the regular fast moving pre- $\beta$ very low-density lipoprotein band. This electrophoretic phenomenon has been called double pre- $\beta$ lipoproteinemia. The prevalence of double pre- $\beta$ lipoproteinemia increased significantly with the degree of impairment of renal function, reaching highest figures in patients on hemodialysis. Accordingly, the very low-density lipoprotein cholesterol/triglyceride ratio also was significantly increased. The double pre- $\beta$ lipoproteinemia phenomenon was not detected in any of the control, nonuremic subjects. The clinical importance of double pre- $\beta$ lipoproteinemia in uremic plasma is related to its possible atherogenic role. (Pediatr Res 21: 462-465, 1987)
\end{abstract}

\section{Abbreviations}

DPBL, double pre- $\beta$ lipoproteinemia

VLDL, very low-density lipoproteins

HDL-CH, high-density lipoprotein cholesterol

AGE, agarose gel electrophoresis

TG, triglyceride

TC, cholesterol

GFR, glomerular filtration

CRI, chronic renal insufficiency

$\mathrm{CrCl}$, creatinine clearance

HD, hemodialysis

T3, triiodothyronine

T4, thyroxine

TSH, thyroid-stimulating hormone

HTGL, hepatic triglyceride lipase

LPL, lipoprotein lipase

Received May 29, 1986; accepted December 9, 1986.

Correspondence to Prof. Graziella Zacchello, Dipartimento di Pediatria, Via Giustiniani, no. 3, I-35128, Padova, Italy.
Complex and characteristic lipid-lipoprotein abnormalities have been described in both adult and pediatric uremic patients receiving conservative treatment or hemodialysis. Hypertriglyceridemia, Frederickson type IV, associated with a consistent decrease in HDL-CH levels, represents the most common dyslipoproteinaemic disorder in these patients (1-5). Another unusual lipoprotein abnormality in uremic adults consists of an additional slow migrating pre- $\beta$ VLDL band on AGE with an intermediate position between the regular fast-moving pre- $\beta$ and $\beta$ bands. This additional pre- $\beta$ band, also called "late pre- $\beta$ " $(6-8)$ or DPBL $(9,10)$, probably is constituted of partially degraded VLDL particles, so called "remnants," similar to those found in type III hyperlipoproteinemia (Fig. 1). In fact, compared to regular fast-moving VLDL, this slow pre- $\beta$ VLDL population is TG poor and $\mathrm{CH}$ enriched, thus explaining the higher VLDL$\mathrm{TC} / \mathrm{TG}$ ratio; moreover its apoprotein-B content is significantly increased while the apoprotein-C peptide level is markedly reduced $(9,11)$.

The clinical importance of detecting consistent amounts of remnant VLDL particles in the plasma of uremic patients relates to their potentially atherogenic role $(12,13)$. In fact DPBL might be an additional risk factor for onset of the accelerated atherosclerotic vascular disease so frequently observed in uremic patients $(14,15)$. To date the DPBL phenomenon has been described only in uremic adults, not in children and adolescents.

The aim of the present study was to evaluate the spectrum of serum lipid abnormalities and DPBL frequency in a series of uremic children and to correlate these findings with the degree of CRI.

\section{PATIENTS AND METHODS}

Forty-five nonnephrotic children (27 males and 18 females) with various degrees of CRI form the basis of this study (Table 1). The children were assigned to five groups according to decreasing renal function assessed as $\mathrm{CrCl}\left(\mathrm{ml} / \mathrm{min} / 1.73 \mathrm{~m}^{2}\right)$ : group I, $\mathrm{CrCl}=50-70$; group II, 30-50; group III, 10-30; group IV, $<10$, and group $\mathrm{V}$ which consisted of patients on maintenance HD.

None of the patients had diabetes mellitus (normal fasting blood glucose and postprandial urine glucose levels), liver dysfunction (normal prothrombin, bilirubin, transaminases and albumin determinations), or thyroid dysfunction (normal serum T3, T4, TSH assay). Obesity was ruled out by the criterion of weighing $20 \%$ more than the desirable weight. Familial hyperlipidemia was excluded by familial screening of those children in whom serum level of TC and TG exceeded the 95th percentile according to sex and age. In only one case was a familial hypertriglyceridemia (TG) pattern observed; this case was ex- 


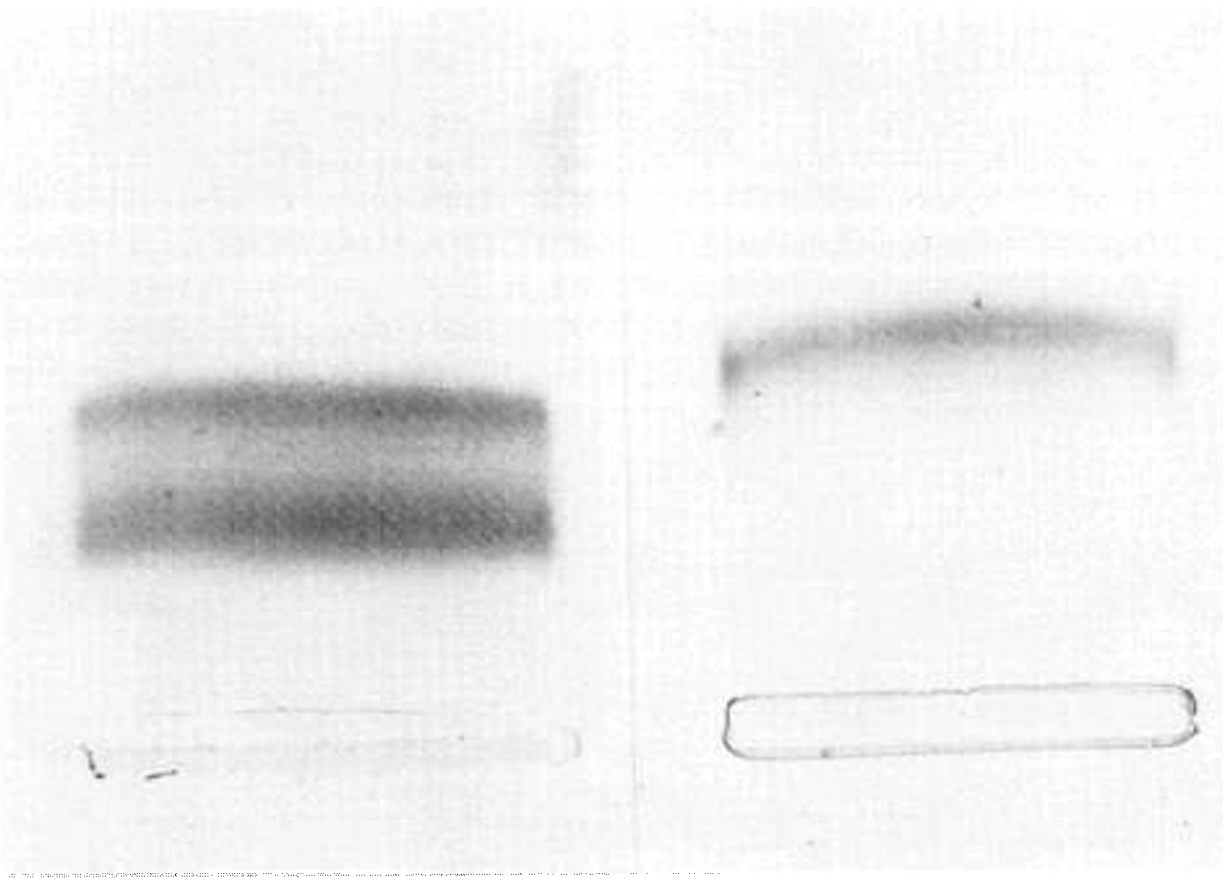

Fig. 1. Age pattern of the VLDL fraction in a uremic child (P.L.). $A$, single prebeta fast moving VLDL band; $B$, an additional prebeta slow moving VLDL band is clearly evident, giving the electrophoretic appearance of two pre- $\beta$ bands, so-called DPBL.

Table 1. Characteristics of various patient groups

\begin{tabular}{cccccc}
\hline Group & $\begin{array}{c}\mathrm{CrCl} \\
\left(\mathrm{ml} / \mathrm{min} / 1.73 \mathrm{~m}^{2}\right)\end{array}$ & $n$ & Males & Females & $\begin{array}{c}\text { Age } \\
(\mathrm{yr})\end{array}$ \\
\hline I & $50-70$ & 10 & 7 & 3 & $8.8 \pm 4.1$ \\
II & $30-50$ & 10 & 7 & 3 & $10.5 \pm 4.9$ \\
III & $10-30$ & 7 & 5 & 2 & $10.7 \pm 3.8$ \\
IV & $<10$ & 8 & 5 & 3 & $11.0 \pm 5.1$ \\
V & Hemodialysis & 10 & 3 & 7 & $13.3 \pm 3.2$ \\
\hline
\end{tabular}

cluded from the study. The underling renal diseases consisted of glomerular nephropathy in four patients, malformative uropathy (reflux nephropathy with or without valve) in 25 , renal hypoplasia in six, nephrophthisis in six, and Fanconi syndrome and cortical necrosis secondary to post-asphytic syndrome in four.

Diet was ascertained by the 3-day record technique; (average) food intake consisted of $8 \%$ proteins $(1-1.5 \mathrm{~g} / \mathrm{kg} /$ day $), 30 \%$ lipids, and $62 \%$ carbohydrates. The diet compliance, which was routinely assessed by an expert dietician, was confirmed by the satisfactory growth of the children (16). Seven of the 45 children (16\%) were hypertensive; these were treated by combination therapy with the following drugs: hydralazine, methyldhopa, and captopril. Five children were taking propanolol; 17 patients received aluminum hydroxide.

The control group consisted of 27 children, with normal GFR as calculated by Schwartz's formula (17); these children were about the same age as the study patients (controls mean age 10.2 yr, range 4-19; cases mean age 10.9 yr, range 2-18; MannWhitney's test $\mathrm{U}=1.54, p=0.12$ ).

Dialysis was performed two or three times weekly for 4-5 h using Gambro Optima filters: the duration of treatment ranged from 2 months to 9 yr (mean 19.8 months \pm SD 33.97). The dialysate contained 135-140 mEq/liter $\mathrm{Na}, 3-3.5 \mathrm{mEq} / \mathrm{liter} \mathrm{Ca}$, $37-38 \mathrm{mEq} /$ liter acetate, $1.5 \mathrm{mEq} /$ liter $\mathrm{Mg}$, and $2 \mathrm{~g} /$ liter dex- trose. Osmolarity ranged from 292 to $303 \mathrm{mOsmol} / \mathrm{liter}$. The heparin dose during $\mathrm{HD}$ was $10-25 \mathrm{mg}$ (intravenous bolus) followed by a constant infusion of $45-95 \mathrm{mg}$.

Blood samples were obtained following an overnight fast, and serum TC, TG, and HDL-CH were determined by standard enzymatic techniques (18-20). Electrophoresis of both serum and the VLDL fraction obtained by preparative ultracentrifugation was performed on agarose gel according to Pagnan et al. (9). Mann-Whitney's test was used to compare TG, TC, and HDL$\mathrm{CH}$ values and the VLDL-TC/TG ratio in each group. The $\chi^{2}$ test with Yate's correction and Fisher's exact test were utilized for the study of DPBB freqency in each group. Frequency of DPBB related to $\mathrm{CrCl}$ was tested by regression analysis.

A preliminary analysis of $\mathrm{HDL}-\mathrm{CH}$ values relative to $\mathrm{CrCl}$ values indicated a relationship between variance and renal function. The result of this regression is described by the following expression:

$$
\begin{aligned}
& \mathrm{y}=48.4816+2.7062 \cdot \mathrm{x}-0.0302 \mathrm{x}^{2} \\
& \mathrm{r}=0.97 \mathrm{SE}=7.27 t=6.86 p<0.01
\end{aligned}
$$

This result indicates that the hypothesis of osmoskedasticity cannot be satisfied. Therefore we used least-square regression analysis of weighted HDL-CH mean values versus $\mathrm{CrCl}$ (weighting HDL-CH mean values by the estimated variances of the observations in each group and their number).

$$
\text { Mean } \mathrm{p}=\frac{\mathrm{x}}{\mathrm{SD}} \cdot n
$$

where mean $\mathrm{p}=$ weighted mean of the group, $\mathrm{x}=$ observed mean of the group, $\mathrm{SD}=$ standard deviation of the group, and $n=$ number of cases in the group.

Several models of regression analysis were fitted, and the goodness of the fit was tested assessing each model's residual variance.

\section{RESULTS}

Mean values and SD of serum TC, TG, and HDL-CH, and the TC/TG-VLDL ratio in the five patient groups and in controls are summarized in Table 2. Serum TC in each patient group was 
Table 2. Mean values and $S D$ of serum $T C, T G, H D L-C H$, $V L D L-T C / T G$ ratio in patients and controls

\begin{tabular}{|c|c|c|c|c|}
\hline Patient groups & $\begin{array}{c}\mathrm{TC} \\
(\mathrm{mg} / \mathrm{dl})\end{array}$ & $\begin{array}{c}\text { TG } \\
(\mathrm{mg} / \mathrm{dl})\end{array}$ & $\begin{array}{c}\text { HDL-CH } \\
(\mathrm{mg} / \mathrm{dl})\end{array}$ & TC/TG-VLDL \\
\hline $\begin{array}{l}\mathrm{I}(n=10) \\
\mathrm{CrCl} 50-70\end{array}$ & $184 \pm 42$ & $89 \pm 39$ & $48 \pm 9.8$ & $0.21 \pm 0.09$ \\
\hline $\begin{array}{l}\text { II }(n=10) \\
\text { CrCl } 30-50\end{array}$ & $174 \pm 35$ & $109 \pm 42^{*}$ & $43 \pm 10.6$ & $\begin{array}{c}0.19 \pm 0.07 \\
(n=7)\end{array}$ \\
\hline $\begin{array}{l}\text { III }(n=7) \\
\text { CrCl } 10-30\end{array}$ & $198 \pm 32$ & $117 \pm 54^{*}$ & $50 \pm 8.9$ & $0.18 \pm 0.03$ \\
\hline $\begin{array}{l}\text { IV }(n=8) \\
\mathrm{CrCl}<10\end{array}$ & $173 \pm 44$ & $179 \pm 97 \dagger$ & $31 \pm 7.9^{*}$ & $\begin{array}{c}0.24 \pm 0.03 \\
(n=7)\end{array}$ \\
\hline $\begin{array}{l}\mathrm{V}(n=10) \\
\mathrm{HD}\end{array}$ & $181 \pm 47$ & $183 \pm 105 \dagger$ & $36 \pm 8.2 \ddagger$ & $\begin{array}{c}0.26 \pm 0.06 \S \\
(n=9)\end{array}$ \\
\hline $\begin{array}{l}\text { Controls } \\
(n=27)\end{array}$ & $158 \pm 27$ & $69 \pm 27$ & $44 \pm 10.3$ & $\begin{array}{c}0.20 \pm 0.06 \\
(n=23)\end{array}$ \\
\hline
\end{tabular}

Significantly different from controls: ${ }^{*} p \leq 0.005 ; \dagger p<0.001 ; \ddagger p \leq$ $0.05 ; \S p<0.02$.

statistically similar to control group values. The serum TG values were significantly increased in patients in group $\mathrm{II}(\mathrm{CrCl} \mathrm{30-50)}$ as compared to controls and group I patients. In addition, significantly higher levels were observed in groups IV and $\mathrm{V}$ (U $=3.10$ and $3.92, p<0.001$ ).

HDL-CH was significantly lower in groups IV and V $(\mathrm{U}=2.9$ and $2.29, p=0.0038$ and 0.02 , respectively) while mean values in groups I, II, and III were similar to controls. A significant difference also emerged between group I and group IV $(\mathrm{U}=$ $2.93, p=0.0035)$ and $\mathrm{V}(\mathrm{U}=2.57, p=0.016)$. The VLDL-TC/ TG ratio was significantly higher $(p<0.02)$ in group V.

The DPBL phenomenon was observed early in chronic renal insufficiency when the GFR value fell below $40-50 \mathrm{ml} / \mathrm{min} / 1.73$ $\mathrm{m}^{2}$. Highest values were seen in group V patients (Table 3 ). The relationship between DPBL frequency and degree of CRI was significant $(p<0.01)$ and may be expressed by a power model (Fig. 2). A significant difference in DPBL frequency also emerged between groups I and V (Fisher's test, $p=0.0126$ ) whereas between groups I and II, and groups III, IV and V, the differences were not significant $\left(\chi^{2}\right.$ test with Yate's correction, $\chi^{2}=3.38, p$ $=0.066$ ).

There appeared to be a significant relationship $(p<0.01)$ between weighted HDL-CH and $\mathrm{CrCl}$ as expressed by a power model (Fig. 3).

The variance of HDL-CH values is strictly correlated with the degree of renal failure $(r=0.97)$. Its tendency is well evaluated by a parabola which shows a peak at $\mathrm{CrCl}$ values between 50 and $30 \mathrm{ml} / \mathrm{min}$ and decreases sharply with further decreases in $\mathrm{CrCl}$ to reach values significantly lower than control levels in children with clearance $<10 \mathrm{ml}$ and in $\mathrm{HD}$. No significant inverse relationship was observed between HDL-CH and serum TG levels.

\section{DISCUSSION}

The results of this study confirm previous reports that hypertriglyceridemia, Frederickson type IV, and low HDL-CH levels represent the most common dyslipidemic disorders in uremic children $(1,5)$ as well as in uremic adults $(2,4)$.

The increase in serum TG occurs early, as reported by Papadopoulous et al. (5), before uremia onset and the levels parallel renal function impairment.

Lowest mean values of HDL-CH were observed in patients with most severe CRI (group IV, $\mathrm{CrCl}<10 \mathrm{ml} / \mathrm{min} / 1.73 \mathrm{~m}^{2}$ ) and in hemodialysis patients (group V); mean values in mild CRF (groups I, II, and III) were similar to control levels.
Table 3. DPBL frequency in various patient groups and in controls

\begin{tabular}{lr}
\hline Group I & $10 \%$ \\
Group II & $25 \%$ \\
Group III & $29 \%$ \\
Group IV & $29 \%$ \\
Group V & $50 \%$ \\
Controls & $0 \%$ \\
\hline
\end{tabular}

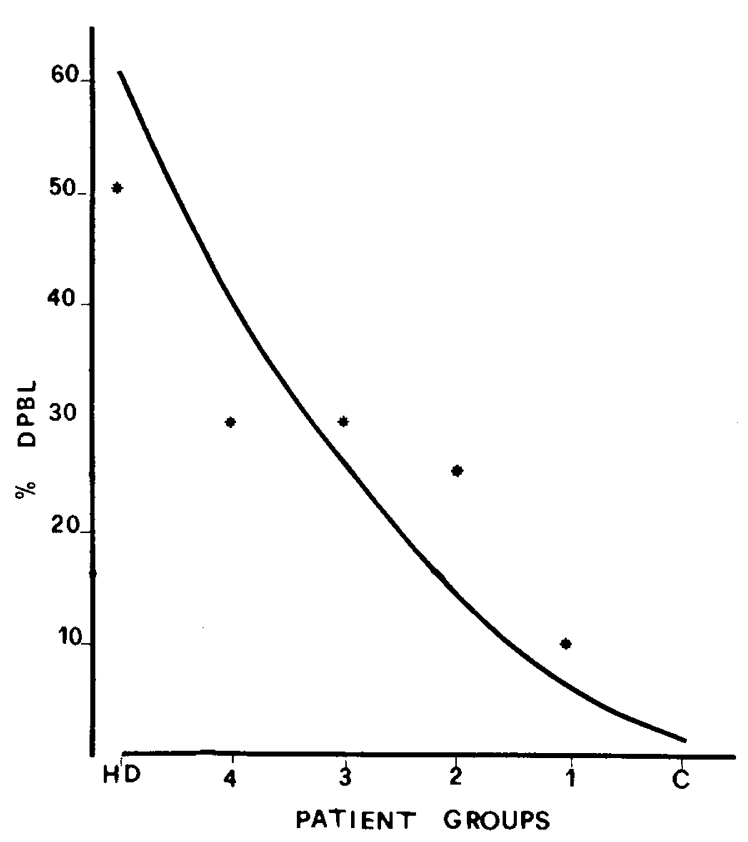

Fig. 2. Relationship between $\mathrm{CrCl}$ and $\mathrm{DPBL}$ frequency. $\mathrm{y}=1.56$ $\mathrm{x}^{2.05} ; \mathrm{r}=0.96 ; \mathrm{SE}=0.46 ; t=6.79 ; p<0.01$.

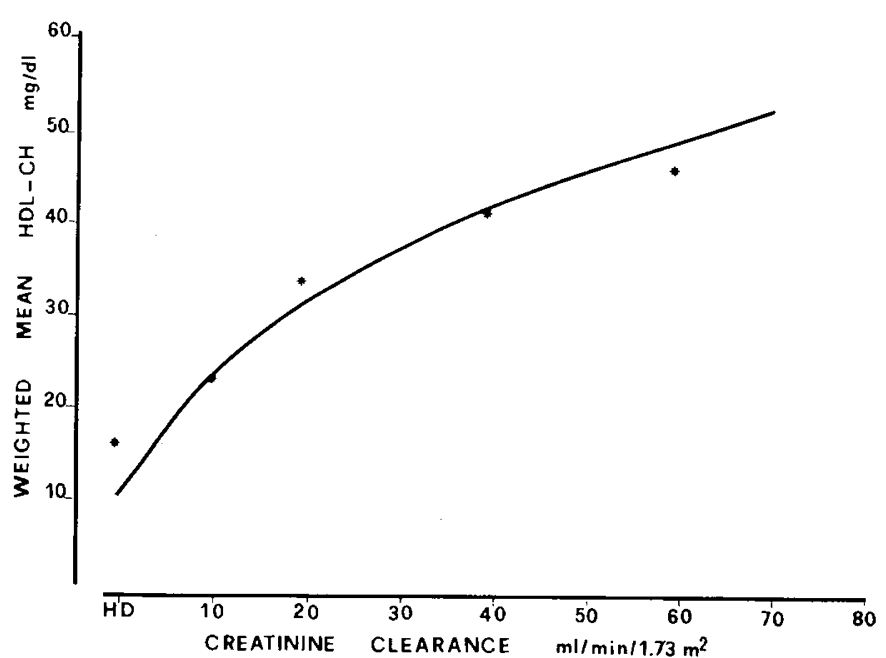

Fig. 3. Relationship between $\mathrm{CrCl}$ and $\mathrm{HDL}-\mathrm{CH}$ weighted mean values. $\mathrm{y}=10.17 \mathrm{x}^{0.39} ; \mathrm{r}=0.95 ; \mathrm{SE}=0.16 ; t=5.2 ; p<0.01$.

The power model of correlation between $\mathrm{CrCl}$ and $\mathrm{HDL}-\mathrm{CH}$ is noteworthy (Fig. 3) and shows an evident decrease in mean weighted $\mathrm{HDL}-\mathrm{CH}$ values when $\mathrm{CrCl}$ is $<40 \mathrm{ml} / \mathrm{min} / 1.73 \mathrm{~m}^{2}$ $(21,22)$. Mean weighted HDL-CH values tend to fall progressively as renal insufficiency progresses. An analysis of the range of these values within each patient group further demonstrated that HDL-CH tends to increase from the first to the second group, where it reaches a maximum value, and then decreases progressively in the successive patient groups to reach a minimum in the HD patients. This might suggest that in group II patients a real fall in HDL-CH levels occurs only in some patients, and the frequency of this fall increases in groups III and IV. This would explain the wide range of HDL-CH values in 
group II, as well as the more evident decrease in mean weighted HDL-CH values in groups III, IV, and V.

Most interestingly, a high frequency of the DPBL phenomenon was documented for the first time in children with CRI. The DPBL frequency increased with impairment in renal function and showed highest figures (50\%) in the HD group (V). Accordingly, the VLDL-TC/TG ratio, which reflects "remnant VLDL" accumulation in plasma, also was significantly increased. This high DPBL frequency in children with CRI, which is similar to that observed in uremic adults (21), contrasts with the observation that this electrophoretic abnormality was not detected in any of the age-matched control children.

This fact clearly indicates that CRI itself is a pathogenic factor for DPBL appearance. Considering the relationship between the DPBL prevalence and renal function impairment, it was interesting to observe that the DPBL increase seemed to have a double-step trend; the first between groups I and II (from 10 to $25 \%$ ) and the second between groups III, IV, and V (from 29 to $50 \%)$. Therefore, in group II not only will a quantitative change in some parameters of lipid metabolism occur in some patients, but there also is a qualitative change with the appearance of different metabolites, indicated by the presence of a double band whose frequency increases at the critical value of creatinine clearance $\left(40 \mathrm{ml} / \mathrm{min} / 1.73 \mathrm{~m}^{2}\right)$. The significance of these data resides in the fact that full expression of the lipoprotein disorder appears when renal function is only moderately impaired.

Regarding the mechanisms underlying this abnormality, several workers have demonstrated that uremic adults, and very recently children with severe $\operatorname{CRF}(1,4,6,22)$ have a marked decrease in the activity of both HTGL and LPL. These enzymatic defects might explain the incomplete hydrolysis of TG-rich VLDL, leading to the plasma accumulation of imperfectly degraded VLDL particles. The detection of important lipid abnormalities in patients with moderate degrees of renal impairment contrasts with the hypothesis of a pathogenic role of heparin during hemodialysis $(2,4)$ as well as with the hypothesis that nondialyzable medium-sized particles are responsible for such disorders (23). On the contrary parathormone might play an important role in the reduced activity of lipolytic enzymes (24).

Nonetheless, the appearance of the DPBL phenomenon might be due to mechanisms other than uremia, such as thyroid hypofunction (25), or an unusual VLDL-apoprotein E pattern characterized by the presence of an additional isoform, so-called EIV (10). The DPBL phenomenon and the reduced serum HDL$\mathrm{CH}$ levels represent two relevant risk factors for the accelerated atherosclerotic cardiovascular disease observed in uremic patients. A further confirmation of the atherogenic role played by DPBL emerges from a family study showing a higher incidence of cardiovascular accidents in family members with the DPBL phenomenon as compared to the control members without DPBL (26).

\section{REFERENCES}

1. Asayama K, Ito H, Nakahara C, Hasegawa A, Kato K 1984 Lipid profiles and lipase activities in children and adolescents with chronic renal failure treated conservatively or with hemodialysis or transplantation. Pediatr Res 18:783788
2. Bagdade JD, Porte D, Bierman EL 1968 Hypertrygliceridemia. A metabolic consequence of chronic renal failure. N Engl J Med 279:181-185

3. Huttenen JK, Pasternack A, Vanttinen T, Ehnholm C, Nikkila EA 1978 Lipoprotein metabolism in patients with chronic uremia. Acta Med Scand 204:211-218

4. Minamisono T, Wada M, Akamatsu 1978 Dyslipoproteinemia (a remnant lipoprotein disease) in uremic patients on hemodialysis. Clin Chim Acta 84:163-172

5. Papadopoulous ZL, Sandler P, Tina LU, Jose PA, Calcagno PL 1981 Hyperlipidemia in children with chronic renal insufficiency. Pediatr Res 15:887891

6. Nestel PJ, Fidge NH, Tan MH 1982 Increased lipoprotein-remnant formation in chronic renal failure. $\mathrm{N}$ Engl J Med 307:329-333

7. Norbeck HE, Carlson LA 1980 Increased frequency of late pre-beta lipoproteins (LPB) in isolated serum very low density lipoproteins in uremia. Eur J Clin Invest 10:423-426

8. Papadopoulous NM, Borer WZ, Elin RJ, Diamond LH 1980 An abnormal lipoprotein in the serum of uremic patients maintained on chronic hemodialysis. Ann Intern Med 92:634-635

9. Pagnan A, Havel RJ, Kane JP, Kotite L 1977 Characterization of human very low density lipoproteins containing two electrophoretic populations double pre-beta lipoproteinemia and primary dysbetalipoproteinemia. J Lipid Res 18:613-622

10. Pagnan A, Zanetti G, Guarini P 1980 Familial study on the "double pre-beta lipoproteinemia" and on polymorphic pattern of apolipoprotein E (EIV "variant" pattern) from human very low density lipoproteins (VLDL). Atherosclerosis 35:351-361

11. Manzato E, Pagnan A, Ziron L, Gasparotto A, Braggion M 1984 Double prebeta lipoprotein. Isolation and characterization of the two populations of very low density lipoproteins by zonal ultracentrifugation. Arteriosclerosis 4:598-603

12. Mahley RW 1982 Atherogenic hyperlipoproteinemia. Med Clin North Am $66: 375-402$

13. Zilversmit DB 1979 Atherogenesis: a post-prandial phenomenon. Circulation 60:473-485

14. Lindner A, Charra B, Sherrard DJ 1975 Accelerated arteriosclerosis in prolonged maintenance hemodialysis. N Engl J Med 290:697-701

15. Lowrie EG, Lazarus JM, Mocelin AJ, Bailey GL, Hampers CL, Wilson RE, Merrill JP 1973 Survival of patients undergoing chronic hemodialysis and renal transplantation. N Engl J Med 288:863-867

16. Rizzoni G, Basso T, Setari M 1984 Growth in children with chronic renal failure on conservative treatment. Kidney Int 26:52-58

17. Schwartz GJ, Haycock GB, Edelmann CMJ, Spitzer A 1976 Pediatrics 58:259263

18. Manual of Laboratory Operations 1974, Vol 75. DHEW Publication, National Institutes of Health, Bethesda, MD, pp 628-635

19. Roschelaw von P, Bernt E, Gruber W 1974 Enzymatische bestimmung des gesant-cholesterins im serum. Z Klin Chem Klin Biochem 12:403-409

20. Wohlefeld AW 1976 Triglyceride determination after enzymatic hydrolisis. In: Bergmeyer HV (ed) Methods of Enzymatic Analysis. Academic Press, New York, pp 1831-1835

21. Braggion M, Pagnan A, Ziron L, Zanetti G, Perin N, Stanic L, Bonadonna A 1984 Rapporto tra funzionalità tiroidea e accumulo nel plasma di VLDL remnant (la "doppia pre-beta lipoproteinemia") in soggetti uremici sottoposti a emodialisi cronica. Giorn Arteriosc 9:129-137

22. Mordasini R, Frey F, Flury W, Klose G, Greten H 1977 Selective deficiency of hepatic triglyceride lipase in uremic patients. N Engl J Med 279:13621366

23. Keshaviah P, Kjellstrand C 1983 Middle molecules: do they exist? Are they toxic? Semin Nephrol 3:295-305

24. Massry SG 1983 The toxic effects of parathyroid hormone in uremia. Semin Nephrol 3:306-328

25. Pagnan A, Casara D, Zanetti G, Guarini P, Braggion M 1980 Serum lipids, "double pre-beta lipoproteinemia," and distribution of the apo-very-lowdensity lipoprotein peptides in hypothyroid patients before and after substitution therapy. Metabolism 29:1026-1030

26. Pagnan A, Zanetti G, Braggion M, Ziron L, Lusiani L, Visona A, Castellani V, Ronsisvalle G 1985 The double pre-beta very low density lipoprotein lipoproteinemia (DPBL): a new dysliproteinemic state. Diabete Metab 11:343-349 